\title{
IMPROVEMENT OF BIMETAL JOINT QUALITY IN SUBMERGED ARC SURFACING OF HIGH-TIN BRONZE ON STEEL
}

\author{
T.B. MAJDANCHUK, V.M. ILYUSHENKO and A.N. BONDARENKO \\ E.O. Paton Electric Welding Institute, NASU \\ 11 Bozhenko Str., 03680, Kiev, Ukraine. E-mail: office@paton.kiev.ua
}

\begin{abstract}
It was shown that one of the efficient methods for producing bimetal product steel + high-tin bronze is submerged electric arc surfacing applying flux-cored wires. Analyzed were the causes for formation of different defects, which are possible in surfacing of bronze on steel. Considered were technological and metallurgical measures of eliminating porosity both on the deposited metal as well as along the fusion line of bronze with steel. To provide a minimum penetration of steel and reduction of iron content in bronze the process is performed using «split» electrode (two-electrode surfacing) at the optimum modes. The special attention is paid to study of causes for formation of intercrystalline penetrations of bronze into steel and their influence on quality of bimetal joint. The threshold value of energy input is determined at which the tendency to decrease the formation of intercrystalline penetrations is observed. 10 Ref., 2 Tables, 4 Figures.
\end{abstract}

Keywords: high-tin bronze, submerged arc surfacing, bimetal joint, intercrystalline penetrations

Due to the high antifriction properties and increased hardness, tin-phosphorous bronze of type $\mathrm{Br} . \mathrm{O} 10 \mathrm{~F} 1$ is widely used in manufacture of bearings, gears and bushings for critical purpose, operating at high specific pressures [1]. In order to save deficient nonferrous metals and increase the strength of bearings it is reasonable to replace the cast bronze parts by bimetal ones. One of the effective methods of manufacturing bimetal products, especially large-sized ones with a working layer of tin bronze of grade Br.O10F1, can be submerged electric arc surfacing. Therefore, the challenging problem is the development of material and technology for surfacing of this type of bronze on steel. As many years of experience of the E.O. Paton Electric Welding Institute show, in surfacing of copper alloys on steel the significant metallurgical and technological difficulties are observed, namely: increased tendency to pores formation (both in deposited metal as well as along the fusion line with steel), intercrystalline penetrations of bronze into steel, and possibility to alloy the deposited metal by iron, a high content of which deteriorates operational properties of the deposited bronze.

As far as the high-tin bronze is not treated by pressure and due to its low ductility it can not be used to produce a small-diameter welding wire, therefore, a flux-cored wire can be used as the electrode material. As a sheath of flux-cored wire, a copper strip of grade M1M (GOST 117393) was used. In the core composition a tin in the form of powder of grade PO-1 (GOST 972373) and phosphorus in the form of powder of phosphorous copper of grade MF-9 (GOST 253084) are included. To prevent porosity in surfacing, the powder of marble is added (up to $5 \%$ ) to the flux-cored wire charge. Marble, refining the electrode metal droplets and reducing the time of their existence at the end of electrode, reduces also overheating of the deposited metal, thus reducing the penetration depth of steel [2].

A significant influence on quality of the bimetal joint has a flux, which is used in surfacing. To select the optimum grade of flux, the influence of different fluxes on the stability of surfacing process, formation of the deposited metal, removal of the slag crust and presence of pores were investigated. Figure 1 shows the appearance of deposits made under fluxes of grades AN-60, AN-348A, AN-26S, AN-60SM and fluoride basic flux UV 420 TT of «Bohler Thyssen» (Germany).

It is characteristic that in three-layer surfacing under the investigated fluxes no cracks and pores were found in the deposited metal during visual inspection, a slag is easily separated, here the best results on process stability were observed under fluxes AN-60 and AN-60SM. In surfacing under fluxes AN-348A and AN-26S during investigation of transverse macrosections the fragmentation and pores in the bead upper part were found in the third layer.

Formation of beads in surfacing under flux UV 420 TT (see Figure 1) was unsatisfactory, 


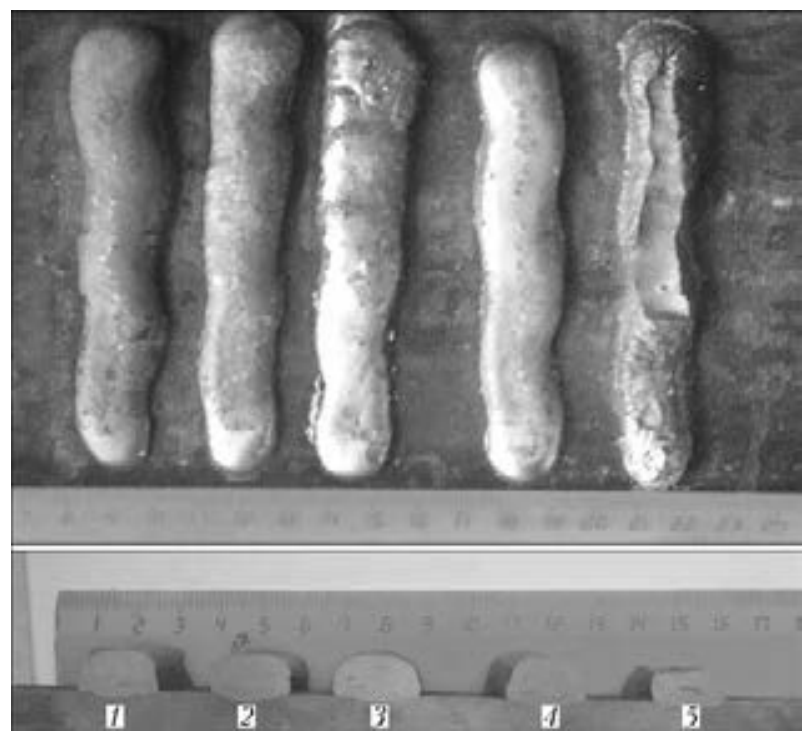

Figure 1. Appearance of deposits made under different fluxes: 1 - AN-60; 2 - AN-348A; 3 - AN-26S; 4 AN-60SM; 5 - UV 420 TT

which may be connected with a high basicity of flux (2.5 points according to Bonishevsky). Therefore, flux AN-60 was used further for surfacing.

In surfacing of copper alloys on steel the pores are often formed along the fusion line. This is connected with a relatively small amount of heat energy, which is introduced in surfacing at the least possible modes to ensure minimization of steel melting, which, on one hand, results in increase of duration of solidification front arrestment and promotes the pores formation [3], and, on the other hand, it results in the volumetric oversaturation of weld pool metal with gases caused by decrease in solubility due to decreasing of metal temperature. In this case, the growth of pores occurs mainly as a result of convective diffusion of gas from the surrounding volumes of metal $[4,5]$. Therefore, the mode of surfacing must be slightly «exceeded» to eliminate this type of defects. At the same time, the increase of mode parameters leads to a large amount of iron, transferred to the deposited metal. It is shown in a number of works $[2,6,7]$ that to reduce penetration of base metal the method of surfacing using split electrode is recommended. The main factor determining penetration depth is the distance between electrodes, i.e. the value of splitting. In order to determine the optimal value of splitting, a single-layer surfacing on lowcarbon steel by flux-cored wire PPBr.OF10-1 at different distance between electrodes was carried out (Figure 2).

The sizes and shape of beads indicate the following. When splitting is less than $6 \mathrm{~mm}$ the common drop of molten metal is formed due to electrodynamic forces during surfacing, which leads to a significant penetration of base metal. In splitting of more than $8 \mathrm{~mm}$ the electrodynamic forces are small, the space between the electrodes is filled with a slag and the arcs begin to burn separately, which results in producing a saddle-shaped deposited metal (see Figure 2) and thus «floating up» of iron-containing particles occurs into the upper part of the bead. The efficiency of the process in surfacing using split electrode is $1.7-2.3$ times increased as compared to a single-electrode surfacing, providing reduction in penetration depth of steel. The decrease in deposition rate from 18 to $10 \mathrm{~m} / \mathrm{h}$, while the other welding parameters are constant, results in up to $5-7 \%$ decrease in iron content in the deposited metal. This is connected with the growth of the layer of molten metal which is leaking under the arc column and thus screening it.

One of the main defects in surfacing of tin bronzes is the intercrystalline penetrations of nonferrous metal into steel. The authors of works $[8,9]$ show that tin bronzes have an increased tendency to intercrystalline penetrations as compared to other copper alloys. At the same time, these defects reduce strength of the joint, they also negatively influence the operation of a product under alternating thermal and dynamic loads.

As metallographic examinations of sections with deposits of tin bronze on steel showed, the

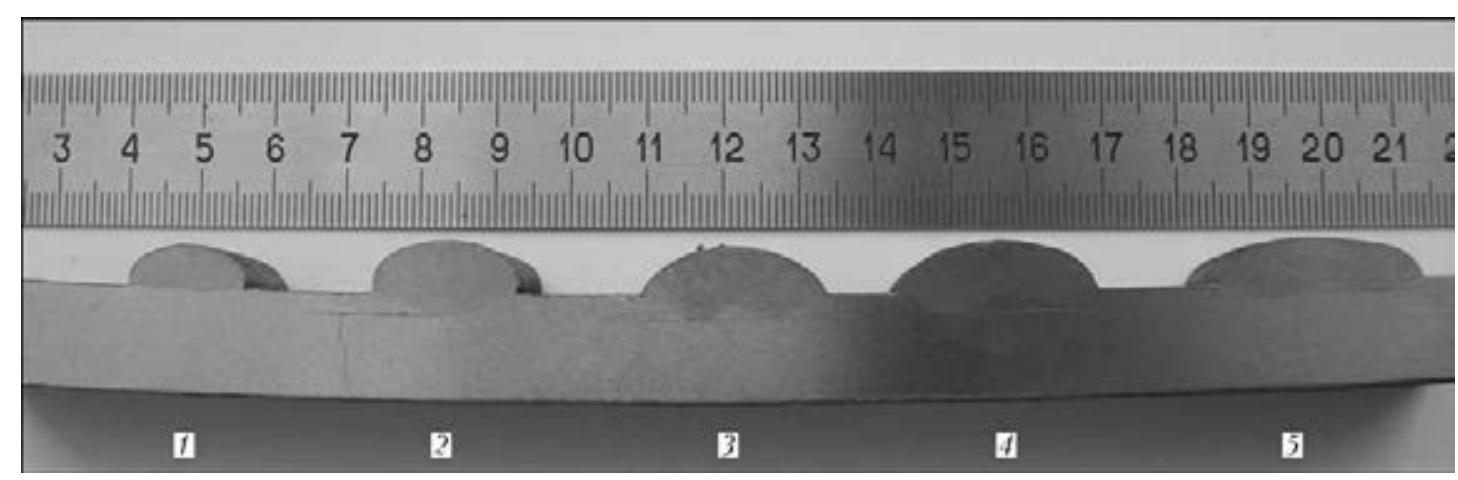

Figure 2. Macrosection of deposits made under flux AN-60 at different distance between the electrodes: $1-1 ; 2-6$; $3-8 ; 4-10.5 ; 5-12 \mathrm{~mm}$ 
Table 1. Effect of surfacing modes on tendency to intercrystalline penetrations of bronze into steel (at $U_{\mathrm{a}}=35 \mathrm{~V}$ )

\begin{tabular}{|c|c|c|c|c|c|c|c|c|}
\hline \multirow{2}{*}{$\begin{array}{l}\text { Number of } \\
\text { deposit }\end{array}$} & \multicolumn{2}{|c|}{ Mode of surfacing } & \multirow{2}{*}{$\begin{array}{l}\text { Energy input, } \\
\mathrm{kJ} / \mathrm{m}\end{array}$} & \multicolumn{3}{|c|}{ Sizes of bead, mm } & \multicolumn{2}{|c|}{ Penetrations } \\
\hline & $I_{\mathrm{s}}, \mathrm{A}$ & $v_{\mathrm{s}}, \mathrm{m} / \mathrm{h}$ & & Width & Height & $\begin{array}{l}\text { Penetration } \\
\text { depth, mm }\end{array}$ & Section I & Section II \\
\hline 1 & 210 & 14 & 496.8 & $14.5-15.5$ & $4.5-5.0$ & $\leq 0.2$ & No & No \\
\hline 2 & 310 & 14 & 669.6 & $20.0-20.5$ & $5.0-5.5$ & $1.5-2.5$ & 2 & No \\
\hline 3 & 390 & 14 & 864 & $24-25$ & $5.3-5.5$ & $1.5-2.5$ & 1 & 2 \\
\hline 4 & 310 & 14 & 478.8 & $14.5-15.0$ & $5.5-6.0$ & $1.0-2.5$ & No & No \\
\hline 5 & 310 & 14 & 576 & $16.5-17.0$ & $5.0-5.5$ & $0.5-1.0$ & No & 2 \\
\hline 6 & 310 & 14 & 669.6 & $19.5-20.0$ & $5.0-5.2$ & $2.5-1.5$ & 2 & No \\
\hline 7 & 310 & 10 & 936 & $20-21$ & $5.0-5.5$ & $\leq 0.5$ & 3 & 2 \\
\hline 8 & 310 & 14 & 669.6 & $19.5-20.0$ & $5.0-5.2$ & $2.5-1.5$ & 2 & No \\
\hline 9 & 310 & 14 & 410.4 & $18.0-18.5$ & $4.0-4.5$ & $\leq 0.5$ & No & No \\
\hline
\end{tabular}

change in concentration in the deposited metal of tin and phosphorus within the limits regulated by GOST 613-79 for the bronze of grade Br.O10F1 (9.0-11.0 \% Sn, 0.4-1.1\% P) has an insignificant effect on amount and extention of intercrystalline penetrations. A more significant influence on presence or absence of penetrations belongs to surfacing modes.

To evaluate the effect of surfacing modes on intercrystalline penetrations the complex of investigations was performed, where in each of the parameters one was changed, and the rest remained unchanged. The surfacing was performed on steel plate of grade St.20 of $12 \mathrm{~mm}$ thickness using split electrode at the distance between axes of $6 \mathrm{~mm}$ using $3 \mathrm{~mm}$ diameter wire PPBr.OF10-1. The templates were cut out of each bead and the presence and nature of intercrystalline penetrations were determined on cross-sections (not less than two sections). The dimensions of bead crosssection as well as penetration depth of base metal

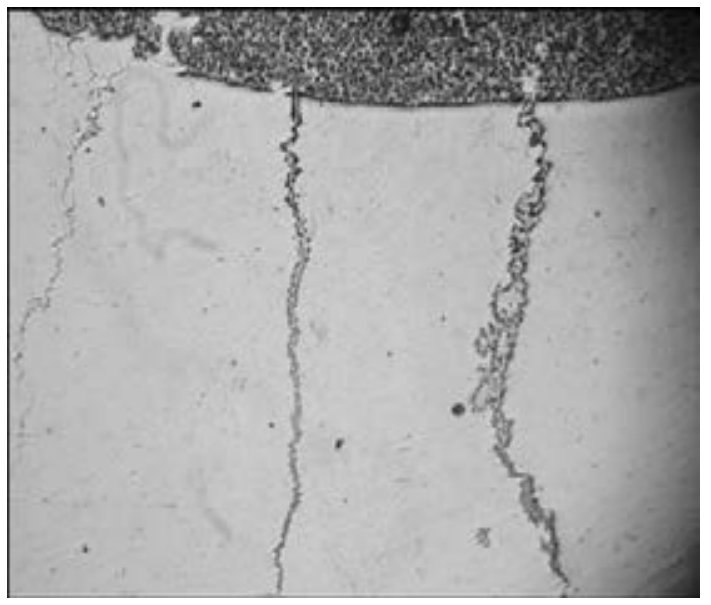

Figure 3. General view of intercrystalline penetration of bronze into steel $(\times 25)$ were recorded. The results of experiments are given in Table. 1.

It is seen from the results given in Table 1 that probability of appearance of intercrystalline penetrations is influenced by all the parameters of welding, but to a greater extent by current and deposition rate than by arc voltage. Moreover, a certain threshold value of heat input exists, below which the intercrystalline penetrations are low probable. For a given method of surfacing it is equal about to $500 \mathrm{~kJ} / \mathrm{m}$.

Any influence of penetration depth on intercrystaline penetrations was not detected. The intercrystalline penetrations are equally probable both during penetration (up to $2.5 \mathrm{~mm}$ ) as well as at almost complete absence of it $(\leq 0.5 \mathrm{~mm})$ i.e. in the samples of deposits 3 and 7 . Heat input in this case is approximately the same. The typical appearance of intercrystalline penetrations is shown in Figure 3.

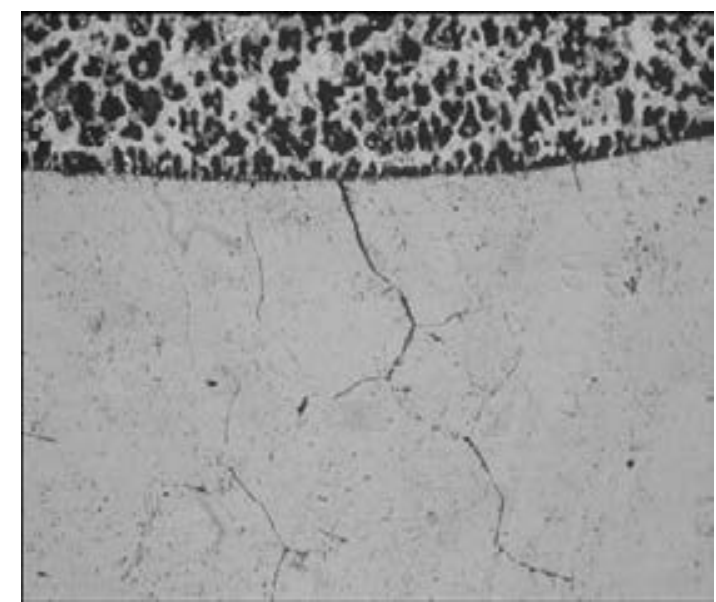

Figure 4. Cracking of steel without filling it with bronze $(\times 156)$ 
Table 2. Chemical composition and mechanical properties of cast and deposited bronzes

\begin{tabular}{|c|c|c|c|c|c|c|c|}
\hline \multirow[b]{2}{*}{ Material } & \multirow[b]{2}{*}{ Sn } & \multirow[b]{2}{*}{$\mathrm{P}$} & \multirow[b]{2}{*}{$\mathrm{Mn}$} & \multirow[b]{2}{*}{$\mathrm{Fe}$} & \multirow[b]{2}{*}{ Hardness $H B$} & \multicolumn{2}{|c|}{ Wear } \\
\hline & & & & & & $\begin{array}{l}\text { Bronze, } \\
\mathrm{mm}^{3} / \mathrm{m}\end{array}$ & $\begin{array}{l}\text { Counterbody, } \\
\mathrm{g} / \mathrm{m}^{*}\end{array}$ \\
\hline Cast bronze of grade Br.O10F1 & $9.0-11.0$ & 0.50 & - & - & $130-140$ & 0.00585 & 0.0013 \\
\hline $\begin{array}{l}\text { Surfacing PPBr.OF10-1 under flux } \\
\text { AN-60 (2nd layer) }\end{array}$ & 9.3 & 0.47 & 0.5 & 2.92 & $150-160$ & 0.0016 & 0.00135 \\
\hline
\end{tabular}

Obviously, the formation of intercrystalline penetration occurs in several stages. At the first stage due to effect of reducing the strength and ductility of steel, which contacts the molten bronze, the fracture occurs at the boundary of steel crystallites (see left side of Figure 3). The presence of initiating crack formations in steel is confirmed by Figure 4, where there is no bronze filling, but separation between the crystallites in steel is clearly seen.

At the next stage the liquid bronze penetrates into the formed crack, which creates an additional pressure on a «wall» of the crack, which leads to its opening. Thus, the crack is opened at a rate of growing to its apex of copper alloy, as even at the end of crack there are no defects such as lack of fusions or voids [10].

The investigations of chemical composition showed that the deposited metal as to its composition corresponds to the cast tin bronze of grade Br.O10F1 (Table 2). Mechanical properties, given in Table 2, indicate that the hardness of deposited metal as compared to the cast one is somewhat higher. In this case wear resistance of the bronze layer deposited under flux is 3-3.5 times higher than that of the cast bronze. It should be noted that the wear of counterbody is almost identical here, from which a conclusion can be made about the same adhesion of steelbronze pairs of friction.

\section{Conclusions}

1. For the surfacing of high-tin bronze on steel the special flux-cored wire was developed providing a high-quality deposited metal of the required composition.
2. In order to reduce iron content in the deposited metal the most effective is to use a split electrode at the optimal surfacing modes.

3. Reduction of tendency to formation of intercrystalline penetrations is achieved due to decrease in heat input.

1. Osintsev, O.E., Fyodorov, V.N. (2004) Copper and copper alloys. Domestic and foreign grades: Refer. Book. Moscow: Mashinostroenie.

2. Ilyushenko, V.M., Lukianchenko, E.P. (2013) Welding and surfacing of copper and copper alloys. Kiev: IAW.

3. Grigorenko, G.M. (1970) To problem of pore formation in welds. Avtomatich. Svarka, 10, 20-29.

4. Pokhodnya, I.K. (1972) Gases in welds. Moscow: Mashinostroenie.

5. Pokhodnya, I.K., Makhnenko, V.I. (1971) On kinetics of pore formation in welds. Avtomatich. Svarka, 7, 20-23.

6. Ilyushenko, V.M., Belov, A.S., Kinovich, A.P. (1985) Efficiency of surfacing of copper alloys on steel with split electrode. In: Surfacing. Experience and efficiency of application, 82-86. Kiev: PWI

7. Ilyushenko, V.M. (1978) Advanced methods of electric arc surfacing of copper alloys on steel. In: Proc. of 1 st All-Union Seminar on Welding and Surfacing of Heavy Nonferrous Metals, 30-32. Kiev: PWI.

8. Vajnerman, A.E., Pichuzhkin, S.A., Chernobaev, S.P. et al. (2012) New welding consumables and technological specifics of welding and surfacing of products of copper alloys and dissimilar metals. In: Proc. of Int. Sci.-Techn. Conf. on Welding Consumables-2012, 141-147.

9. Rybin, V.V., Vajnerman, A.E., Baranov, A.V. at al. (2006) Study of peculiarities and development of welding technologies of copper alloys with steels and surfacing of copper alloys on steel. Voprosy Materialovedeniya, 1, 220-229.

10. Vajnerman, A.E. (1981) Mechanism of intercrystalline penetration in surfacing of copper alloys on steel. Ibid., 6, 22-26. 